\title{
Sistein İçeren Yeni Bir Adsorban Sentezi ve Sulu Ortamdan Pb(II) ve Hg(II) İyonlarının Giderimi
}

\author{
Synthesis of A New Cysteine Containing Adsorbent and Removal of Pb(II) and $\mathrm{Hg}$ (II) Ions From \\ Aqueous Media
}

\author{
Sabahattin DENIZ1 ${ }^{10}$, Güler DARTAN² (D), Yalçın Kaan TÜRKMENOĞLU ${ }^{2}$ \\ ${ }^{1}$ Marmara Üniversitesi Teknoloji Fakültesi Tekstil Mühendisliği Bölümü 34722 Göztepe Kampüsü, ISTANBUL \\ ${ }^{2}$ Marmara Üniversitesi Fen Edebiyat Fakültesi Kimya Bölümü 34722 Göztepe Kampüsü, ISTANBUL
}

\section{Öz}

Sulu ortamlardaki ağır metal kirliliği canlı hayatı için çok önemli sorunlara neden olabilmektedir. Pek çok organik kirleticilere göre sulu ortamda daha kararlı bir yapıda bulunabilmeleri ve biyolojik ortamlarda birikebilmeleri çevre sağlığı açısından geri dönülemez zararlara neden olabilmektedir. Gelişen ve artan sanayii üretimi atık olarak pek çok ağır metal oluşturmakta ve bunların kontrolsüz deşarjı temiz su kaynaklarının azalmasına neden olmaktadır. Bu sebeple sulu ortamdan ağır metal giderimi tüm canlılar için oldukça önemli bir konudur.

Bu çalışmada 3-aminopropilsilika sistein ile modifiye edilerek yeni bir adsorban sentezlendi ve karakterize edildi. Ardından sentezlenen bu adsorbanın $\mathrm{Pb}$ (II) ve $\mathrm{Hg}$ (II) iyonları için adsorpsiyon kapasitesi incelendi. Maksimum adsorpsiyon için en uygun şartlar (temas süresi, $\mathrm{pH}$ ) belirlendi. Sentezlenen adsorbanın $\mathrm{Pb}(\mathrm{II})$ ve $\mathrm{Hg}$ (II) iyonları için $\mathrm{pH}=6$ ' da 60 dakikada maksimum adsorpsiyon kapasitesi sırasıyla 12,32 \pm 0,2 ve $100,6 \pm 0,2 \mathrm{mg} \mathrm{g}^{-1}$ olarak belirlendi.

Anahtar kelimeler: Adsorpsiyon, Sistein, Ağır metal, Kurşun, Cıva

\begin{abstract}
The heavy metal pollution in aqueous media can cause very important problems for living life. Compared to many organic pollutants, they can cause irreversible damages in terms of environmental health because they are more stable in aqueous environment and accumulate in biological environments. Developing and rising industrial production generates many heavy metals as waste, and their uncontrolled discharge causes a decrease in the clean water resources. Therefore, removal of heavy metals from aqueous environments is a crucial issue for all living species.

Presently, there is growing interest removing of heavy metal ions by adsorption methods in the use of modified silica gel. Silica gel has great importance as a solid support. In this work silica gel is chosen for the preparation of modified products because of having a lot of advantages such as high surface area, high mechanical endurance and thermal stability.

This study consists of two steps. First is modification of 3-aminopropylsilica with cysteine and characterized and second is determination of adsorption capacity of this adsorbent for $\mathrm{Pb}$ (II) and $\mathrm{Hg}$ (II) ions and optimum conditions (contact time, $\mathrm{pH}$ ) for maximum adsorption. For determining of optimum conditions, adsorption experiments have been carried out at the $\mathrm{pH}$ range of 3 - 7 and contact time range of $10-120$ minutes. The maximum adsorption capacity in 60 minutes at $\mathrm{pH} 6$ for $\mathrm{Pb}$ (II) and $\mathrm{Hg}$ (II) ions were determined such as $12.32 \pm$ 0.2 and $100.6 \pm 0.2 \mathrm{mg} \mathrm{g}^{-1}$, respectively. The adsorption studies also have been carried out at optimum conditions in synthetic wastewater and tap water by spiking heavy metal ions. The results showed that foreign ions have not any negative effect on adsorption of $\mathrm{Pb}$ (II) but unfortunately, they have on adsorption of $\mathrm{Hg}$ (II) ions. Having such satisfactory adsorption results, cysteine modified 3-aminopropylsilica is a potential candidate adsorbent for $\mathrm{Pb}(\mathrm{II})$ and $\mathrm{Hg}(\mathrm{II})$ removal from aqueous media.
\end{abstract}

Keywords: Adsorption, Cysteine, Heavy metal, Lead, Mercury 


\section{I.GiRiş}

Canlı yaşamının temel kaynağı şüphesiz ki sudur. Yerküremizin yaklaşık \%70' inden fazlasının suyla kaplı olmasına rağmen tatlı su kaynakları oldukça kısıtlıdır. Su kaynaklarının bilinçsiz kullanımı, kullanıma uygun su talebindeki artışlar, yer altı ve yer üstü su kalitesinin bozulması gibi sebepler çok yakın zamanda su kıtlı̆̆ına neden olabilecek sebeplerden sayılabilir [1].

Dünya nüfusunun hızlı artışı, sanayileşmenin aşırı artması ancak buna paralel olarak çevre bilincinin bu hızda gelişmemesi kullanılabilir su kaynaklarını hızla tüketmektedir. Özellikle sanayileşmenin hızlı artması getirdiği pek çok avantaj yanında ürettiği atıklar nedeniyle çevre ve dolayısıyla canlılar için önemli tehditler oluşturmaktadır.

Çeşitli sanayii kuruluşlarının ürettiği zararlı atıkları genel olarak organik ve anorganik atıklar olarak iki sınıfa ayırabiliriz. Bunlardan organik atıklar anorganik atıklara göre çevre ortamında daha dayanıksız olabilmektedir. Ancak anorganik atıklar özellikle sulu ortamlarda uzun zaman bozunmadan kalabilmekte ve birikimlere neden olabilmektedirler. Anorganik atıklar dendiğinde ise akla çoğunlukla ağır metaller gelmektedir.

Ağır metaller için çeşitli tanımlar yapılabilmektedir. Bu metallere "ağır metal" denmesinin sebebi fiziksel özellikleri bakımından yoğunluklarının $5 \mathrm{~g} \mathrm{~cm}^{3}$ ' ten daha fazla olmalarıdır. Bu şekilde tanımlanabilecek içlerinde demir, bakır, kurşun, çinko, nikel, kobalt, civa, kromun da olduğu 60' dan fazla ağır metal vardır [2].

Her ne kadar ağır metal dendiğinde pek çoğumuzun aklına sadece zehirli etkileri gelse de aslında ağır metaller biyolojik süreçteki etki derecelerine göre yaşamsal ve yaşamsal olmayan olarak iki sınıfa ayrılabilirler. Bunlardan demir, bakır, çinko, nikel ve selenyum bazı biyokimyasal reaksiyonlarda kofaktör olarak rol oynamaları sebebiyle organizma yapısında belirli düzeylerde bulunmaları gerekmektedir. Ancak belirli bir derişimin (1-10 ppm) üstünde olduklarında toksik etki gösterirler. Ancak kurşun, cıva ve kadmiyum gibi ağır metallerin çok düşük derişimleri bile toksik etkiye sahiptir. Ağır metallerin insan sağllğı üzerine etkileri psikolojik bozukluklardan başlar deri, sindirim, kardiyovasküler, hormon ve immün sistem problemlerini de içeren pek çok fizyolojik probleme sebep olurlarken ve en nihayetinden pek çok kanser oluşumuna da sebep olmaktadırlar [3].

Bazı ağır metal tuzları suda iyi çözünmeleri nedeniyle sulu ortamlara kolaylıkla karışırlar. Bunların pek çoğu da suda renksiz olarak çözündüklerinden ağır metal ile kirlenmiş suların kolaylıkla fark edilmesi imkânsızdır. Çeşitli sanayi kuruluşlarından sulu ortamlara karışan ağır metal iyonları özellikle deniz, akarsu ve göllerin sedimanlarında az çözünür tuzları halinde çökelti oluştururlar. Böylelikle suda çözünmüş ağır metal azaldığında sedimanlar suya ağır metal iyonlarını salarlar. Bu durum ağır metal kirliliğinin ne kadar tehlikeli olabileceğini göstermektedir. Bu şekilde ağır metal iyonları ile kirlenmiş sularda yaşayan canlılar, bünyelerine ağır metalleri alırlar ve ağır metaller sucul ortamlarda en küçük canlının bünyesinden besin zinciri ile diğer canlının bünyesine konsantrasyonu artarak geçer ve pek çok canliyı tehdit ederler.

Tüm bu olumsuzluklar düşünüldüğünde ağır metal gideriminin önemi daha iyi anlaşılmaktadır. Sulardan ağır metal giderimi için çeşitli yöntemler kullanılmaktadır. Bunlar; sıvı-sıv1 ekstraksiyon, iyon değişimi, çöktürme, ters ozmos ve adsorpsiyondur [4-7]. Bunlar arasında adsorpsiyon yöntemi, ağır metallerin veya diğer kirleticilerin sulu ortamdan bir katı yüzeyine tutturularak ortamdan uzaklaştırılmasında sıklıkla kullanılmaktadır [8]. Son yıllarda adsorbanların kapasitesini arttırmak ve ortamda başka iyonlar da varken seçim metal iyonlarını uzaklaştırmak için seçimli adsorpsiyon çok önemli bir konu haline gelmiştir $[9,10]$.

Bu çalışmada; silika esaslı mikro partiküllerin sistein ile modifiye edilerek yeni bir adsorban sentezlenmiş ve karakterize edilmiştir. Sentezlenen bu adsorbanın farklı miktarlarda $\mathrm{Pb}$ (II) ve $\mathrm{Hg}$ (II) iyonu içeren numunelerdeki $\mathrm{Pb}(\mathrm{II})$ ve $\mathrm{Hg}$ (II) iyonlarının maksimum adsorpsiyonu için optimum ortam şartları belirlenmiştir.

\section{MATERYAL VE YÖNTEM}

\section{I. Kullanılan Kimyasal Maddeler ve Cihazlar}

Deneylerde; 3-Aminopropil silika jel (40-63 $\mu \mathrm{m}, \sim 1$ mmol g${ }^{-1}$ NH2 içerir) sistein ve sodyum asetat trihidrat Sigma-Aldrich marka, glutaraldehit (\%25 sulu çözeltisi), etanol, kurşun (II) nitrat, cıva (II) nitrat monohidrat Merck, $1000 \mathrm{mg} \mathrm{L}^{-1}$ ' lik Pb (II) ve Hg (II) standart çözeltiler Merck marka kullanılmıştır. Deneylerde 18,2 $\mathrm{M} \Omega \mathrm{cm}^{-1}$ dirence sahip saf su kullanılmış ve Millipore Milli Q-water purification system ultra saf su cihazından elde edilmiştir.

FT-IR ölçümleri Perkin-Elmer marka ATR-FTIR cihazı ile yapılmıştır. Kurşun ve cıva analizleri için Analytik Jena marka ZEEnit 700P model alevli atomik absorpsiyon spektrofotometresi kullanılmıştır. Tartım işlemlerinde Precisa XB 220 A model 0,001g hassasiyete sahip analitik terazi, düşük hacimlerdeki çözeltilerin ve çözücülerin aktarımı için Eppendorf Research Plus marka $100-100 \mu \mathrm{L}$ ve $100-1000 \mu \mathrm{L}$ otomatik pipetler, $\mathrm{pH}$ ölçümleri yapmak için Mettler Toledo $\mathrm{pH}$ metre ve çözeltilerin karıştırılmasında Heidolph marka MR $3001 \mathrm{~K}$ model manyetik karıştırıcı kullanılmıştır. 
Santrifüj işlemlerinde ise Hettich marka EBA 21 model santrifüj cihazı kullanılmıştır.

\subsection{Yöntem}

Bu çalışma iki aşamadan oluşmaktadır.

- İlk aşamada $\mathrm{Pb}(\mathrm{II})$ ve $\mathrm{Hg}(\mathrm{II})$ iyonları için spesifik olacağ düşünülen silika esaslı modifiye adsorban sentezlendi ve yapısı aydınlatıldı.

- İkinci aşamada ise sentezlenen adsorbanın farklı konsantrasyonlarda $\mathrm{Pb}(\mathrm{II})$ ve $\mathrm{Hg}$ (II) iyonları içeren sulu çözeltilerle muamele edilerek adsorpsiyon kapasitesi tespit edildi ve maksimum adsorpsiyon yapacağı optimum şartlar belirlendi.

\subsection{Adsorbanın sentezi}

2 gram 3-Aminopropil Silika, 60 mL glutaraldehit çözeltisine azar azar ve yavaşça ilave edildi. Maddeler $750 \mathrm{rpm}$ karıştırma hızında 2 saat boyunca oda sıcaklığında karıştırıldı. Sonrasında oluşan kahverengimsi katı madde saf su ve etanol ile yıkandı ve 4500 rpm' de 5 dakika santrifüj edilerek ayrıldı. Bu yıkama işlemi 5 defa yapıldı. Bu aşamadaki reaksiyon Şekil 1. deki gibidir.

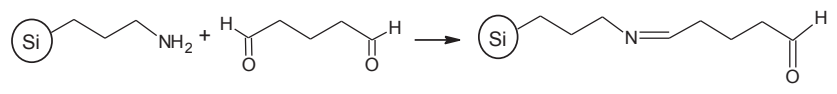

Şekil 1. 3-Aminopropil Silika ile Glutardialdehitin Reaksiyonu

0,5 gram L-sisteinin bir miktar saf suda çözülmesiyle ele geçen çözelti, Şekil 1.' deki reaksiyona göre elde edilen madde ile karıştırıldı ve oda sıcaklığında 750 rpm' de bir gece karışmaya bırakıldı. Reaksiyon bittikten sonra elde edilen adsorban madde saf su ve etanol ile yıkanarak 4500 rpm' de 5 dakika santrifüj edildi. Ardından dekante edilerek katı madde ayrıldı. Ele geçen katı adsorban vakum etüvünde $40^{\circ} \mathrm{C}$ ' de 3 saat kurutuldu. Bu aşamadaki reaksiyon Şekil 2. deki gibidir.

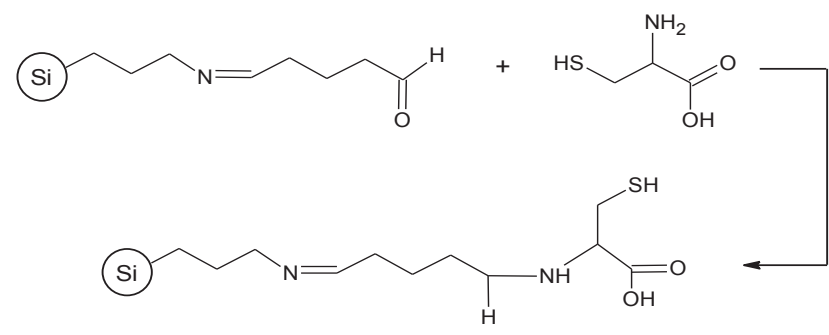

Şekil 2. 3-Aminopropilsilika ve Glutaraldehitin Reaksiyon Ürünü ile L-Sisteinin Reaksiyonu

\subsection{Adsorpsiyon çalışmaları}

Sentezlenen adsorbanın $\mathrm{Pb}(\mathrm{II})$ ve $\mathrm{Hg}$ (II) iyonları için adsorpsiyon kapasitesini belirlemek için $0,1 \mathrm{~g}$ adsorban farklı konsantrasyonlarda metal çözeltileri ile, $\mathrm{pH} 3-7$ aralığındaki tampon çözeltilerde ve 10 - 120 dakika temas sürelerinde manyetik karıştırıcı ile karıştırıldı. Her bir çalışmada adsorban ve çözelti $4500 \mathrm{rpm} 5$ dakika santrifüjlenerek ayrıldı. Santrifüj sonrası ele geçen çözelti PTFE filtre ile süzüldükten sonra çözelti Alevli Atomik Absorpsiyon (AAAS) ile analiz edildi. Tüm analizler üçer defa tekrar edildi ve sonuçların ortalaması $\% 95$ güven aralığında verildi. Çalışmamızdaki ölçümlerin belirsizlik bütçesi; AAS cihazı, pH metre, analitik terazi, kantitatif cam ölçü kapları (pipet, balonjoje) ve manyetik karıştırıcıdan gelen belirsizliklerin toplamından oluşmaktadır.

\section{BULGULAR}

\section{I. Karakterizasyon}

3-aminopropil silikanın sistein ile modifiye edilmesiyle elde edilen adsorban ve başlangıç maddelerinin ATR-FTIR spektrumları Şekil 3. de gösterilmiştir. Sentezlenen adsorbana ait spektrumda $3363 \mathrm{~cm}^{-1}$ de $-\mathrm{OH}$ gerilmesine ait pik, $3048 \mathrm{~cm}^{-1} \mathrm{de}-\mathrm{CH}_{2}$ gerilme ait pik, $2550 \mathrm{~cm}^{-1} \mathrm{de}-\mathrm{SH}$ gerilmesine ait pik, $1742 \mathrm{~cm}^{-1}$ de sistein molekülünün karboksil karboniline ait gerilme pik, $1571 \mathrm{~cm}^{-1}$ de $\mathrm{C}=\mathrm{N}$ gerilmesine ait pik, $1517 \mathrm{~cm}^{-1}$ de $\mathrm{C}=\mathrm{N}$ titreşimine ait pik, $1623 \mathrm{~cm}^{-1} \mathrm{de}$ $-\mathrm{CS}$ gerilmesine ait pik, $1207 \mathrm{~cm}^{-1} \mathrm{ve} 1057 \mathrm{~cm}^{-1} \mathrm{de}-\mathrm{CO}$ gerilmesine ait pik ve $777 \mathrm{~cm}^{-1} \mathrm{de},=\mathrm{CH}$ gerilmesine ait pikler gözlenmiştir [11,12].

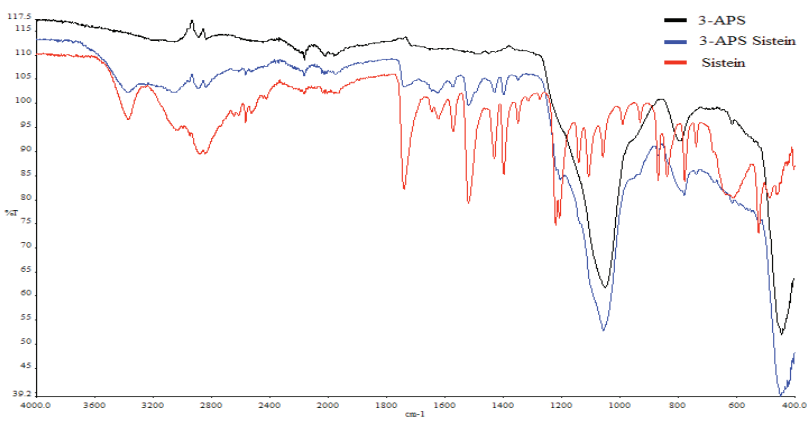

Şekil 3. Adsorban ve Başlangıç Maddelerinin FTIR spektrumu

\section{2. pH Etkisi}

$\mathrm{Pb}$ (II) ve $\mathrm{Hg}$ (II) iyonlarının adsorpsiyonuna ortam pH' ının etkisini incelemek amaciyla $\mathrm{pH} ; 3,4,5,6$ ve 7 değerlerinde 100 ppm konsantrasyonlarında hazırlanan 
çözeltilerden 20' şer mL alındı. Bu çözeltilerin üzerine 0,1 gram sentezlenen adsorban madde ilave edildi. Adsorpsiyonun hangi $\mathrm{pH}$ değerinde daha etkili olduğunun incelenmesi amacıyla elde edilen karışım 90 dakika manyetik karıştırıcıda karıştırıldı. Sonuçlar Şekil 4.' te gösterilmiştir. Buna göre sistein modifiyeli silika adsorbanı $\mathrm{Pb}$ (II) ve $\mathrm{Hg}$ (II) iyonları için $\mathrm{pH}=6$ ' da maksimum adsorpsiyon gözlendi.

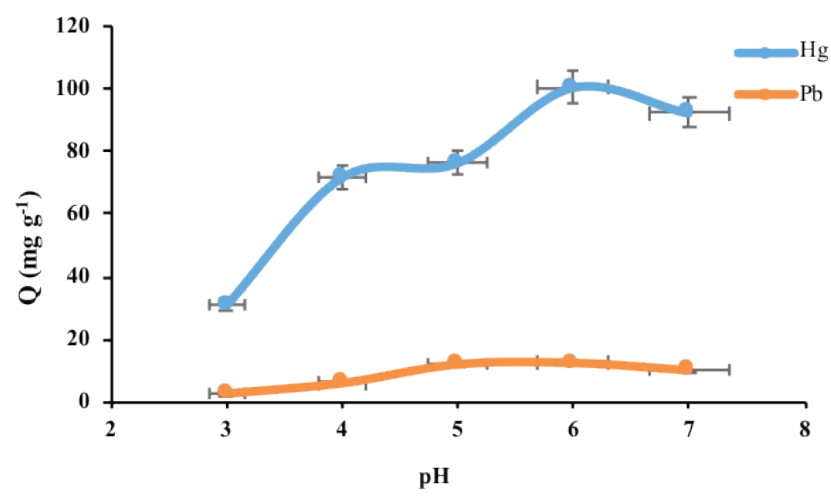

Şekil 4. $\mathrm{Pb}(\mathrm{II})$ ve $\mathrm{Hg}(\mathrm{II})$ Adsorpsiyonuna pH' in Etkisi

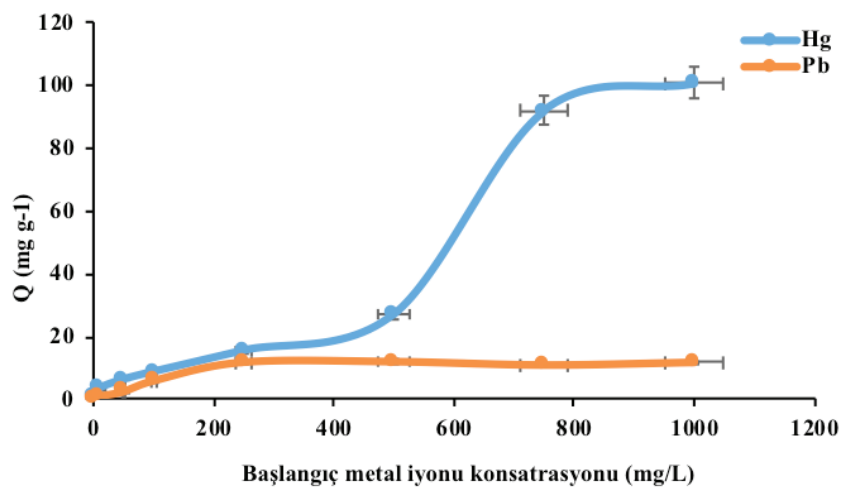

Şekil 5. $\mathrm{Pb}(\mathrm{II})$ ve $\mathrm{Hg}(\mathrm{II})$ Adsorpsiyonuna başlangıç konsantrasyonun etkisi

\subsection{Temas Süresi}

Adsorbanla çözeltinin temas süresinin adsorpsiyona etkisi incelemek amacıyla; $\mathrm{pH}=6^{\prime} \mathrm{da}, \mathrm{Pb}$ (II) için
250 ppm ve $\mathrm{Hg}(\mathrm{II})$ için 750 ppm' lik çözeltilerle 10 120 dakika aralığında manyetik karıştırıcıda karıştırılarak her bir durum için analizler yapıldı. Sonuçlar Şekil 6.' da gösterildi. Elde edilen sonuçlara göre her iki iyon için de 60 dakikada maksimum adsorpsiyona ulaşıldığ 1 ve adsorpsiyon değerlerinin bu süreden sonra sabit kaldığg gözlendi.

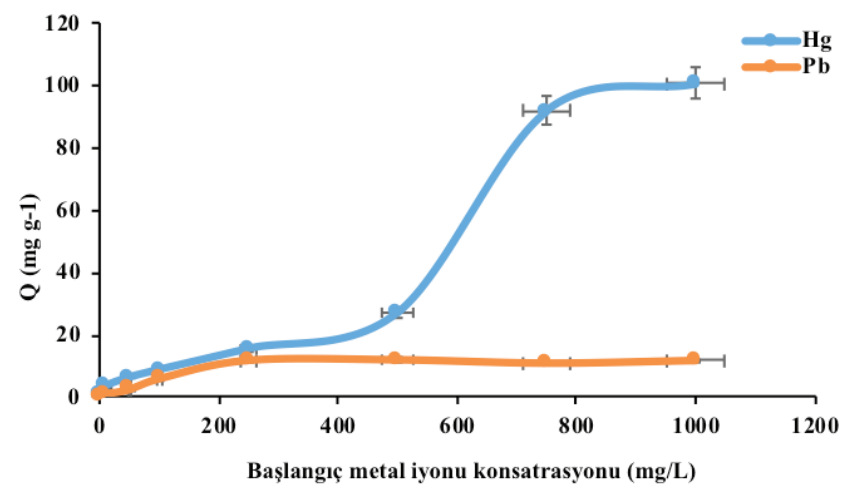

Şekil 6. $\mathrm{Pb}(\mathrm{II})$ ve $\mathrm{Hg}(\mathrm{II})$ Adsorpsiyonuna temas süresinin etkisi

\subsection{Yabancı İonların Etkisi}

Sulu ortamda bulunabilecek başka iyonların adsorpsiyona etkisini incelemek için hazırlana sentetik atık suyuna [13] ve musluk suyuna $\mathrm{Pb}(\mathrm{II})$ ve $\mathrm{Hg}$ (II) iyonlarından son konsantrasyonları 100 ppm olacak şekilde ilave edildi ve $\mathrm{pH}=6$ ' da 60 dakika süre ile adsorbanla karıştırıldı. Elde edilen sonuçlar Tablo 1.' de gösterilmiştir.

\section{SONUÇ VE TARTIŞMA}

$\mathrm{Bu}$ çalışmada 3-aminopropil silika, sistein ile modifiye edilerek yeni bir adsorban sentezlendi. Sentezlenen bu adsorbanın yapısı FTIR ile karakterize edildi. Adsorbanın, $\mathrm{Pb}$ (II) ve $\mathrm{Hg}$ (II) iyonları için maksimumu adsorpsiyon için gerekli optimum şarlar belirlendi. Elde edilen sonuçlar Tablo 2.' de gösterilmiştir.

Tablo I. $\mathrm{Pb}(\mathrm{II})$ ve $\mathrm{Hg}(\mathrm{II})$ iyonlarının farklı ortamlardaki adsorpsiyonu

\begin{tabular}{|c|c|c|c|c|c|c|}
\hline \multirow{2}{*}{$\begin{array}{l}\text { Metal } \\
\text { iyonu }\end{array}$} & \multicolumn{2}{|l|}{$\mathrm{Saf} \mathrm{Su}$} & \multicolumn{2}{|c|}{ Sentetik Atık Su } & \multicolumn{2}{|l|}{ Musluk Suyu } \\
\hline & $\mathrm{mg} \mathrm{g}^{-1}$ & $\mathrm{mmol} \mathrm{g}^{-1}$ & $\mathrm{mg} \mathrm{g}^{-1}$ & $\mathrm{mmol} \mathrm{g}{ }^{-1}$ & $\mathrm{mg} \mathrm{g}^{-1}$ & $\mathrm{mmol} \mathrm{g}^{-1}$ \\
\hline $\mathrm{Pb}(\mathrm{II})$ & $12,32 \pm 0,2$ & $0,059 \pm 0,001$ & $14,2 \pm 0,1$ & $0,069 \pm 0,003$ & $10,75 \pm 0,04$ & $0,052 \pm 0,006$ \\
\hline $\operatorname{Hg}(\mathrm{II})$ & $100,60 \pm 0,2$ & $0,502 \pm 0,002$ & $29,34 \pm 0,07$ & $0,146 \pm 0,002$ & $53,8 \pm 0,1$ & $0,268 \pm 0,002$ \\
\hline
\end{tabular}


Tablo 2. $\mathrm{Pb}$ (II) ve $\mathrm{Hg}$ (II) iyonlarının adsorpsiyonu için optimum şartlar

\begin{tabular}{ccccc}
\hline $\begin{array}{c}\text { Metal } \\
\text { İyonu }\end{array}$ & $\mathbf{p H}$ & $\begin{array}{c}\text { Başlangıç } \\
\text { Konsantrasyonu } \\
\left(\mathbf{m g . ~ L}^{-1}\right)\end{array}$ & $\begin{array}{c}\text { Temas } \\
\text { Süresi } \\
\text { (dakika) }\end{array}$ & $\begin{array}{c}\text { Adsorpsiyon } \\
\text { Miktarı }\left(\mathbf{m g . g}^{-1}\right)\end{array}$ \\
\hline $\mathrm{Pb}(\mathrm{II})$ & 6 & 250 & 60 & $12,32 \pm 0,2$ \\
$\mathrm{Hg}(\mathrm{II})$ & 6 & 750 & 60 & $100,6 \pm 0,2$ \\
\hline
\end{tabular}

Elde edilen sonuçlara göre; sentezlenen adsorbanın $\mathrm{Pb}$ (II) ve $\mathrm{Hg}$ (II) iyonları için $\mathrm{pH}=6$ ' da 60 dakikada maksimum adsorpsiyon kapasitesi sirasiyla $12,32 \pm 0,2$ ve 100,6 \pm $0,2 \mathrm{mg} \mathrm{g}^{-1}$ olarak belirlendi.

Sentezlenen adsorban maddenin maksimum adsorpsiyon kapasitesi başka adsorbanların adsorpsiyon kapasiteleri ile kıyaslanmış ve sonuçlar Tablo 3.' te verilmiştir. Yapılan bu çalışma farklı çalışmalar ile kıyaslandığında adsorpsiyon kapasitesinin diğer çalışmalara göre nispeten yüksek olduğu görülmektedir. Maksimum adsorpsiyon kapasitesi değerlendirildiğinde bu çalışmada sentezlenen adsorbanın benzerlerine göre daha avantajlı olduğu düşünülmektedir.

Tablo 3. Sentezlenen Adsorbanın Benzer Diğer Adsorbanlarla

\begin{tabular}{|c|c|c|c|c|}
\hline \multicolumn{5}{|c|}{ Karş1laştırılması } \\
\hline Sistem & $\begin{array}{l}\text { Çalışılan } \\
\text { Metal }\end{array}$ & $\mathrm{pH}$ & $\begin{array}{l}\text { Adsorpsiyon } \\
\text { Kapasitesi } \\
\left(\mathrm{mg} \cdot \mathrm{g}^{-1}\right)\end{array}$ & Referans \\
\hline 1,3,4-trithiane & $\mathrm{Pb}$ (II), $\operatorname{Hg}(\mathrm{II})$ & 5 & $9,50-35,5$ & 14 \\
\hline $\begin{array}{l}\text { Choline modifiye } \\
\text { silika jel }\end{array}$ & $\mathrm{Pb}$ (II), $\operatorname{Hg}(\mathrm{II})$ & 7 & $11,7-60,1$ & 15 \\
\hline $\begin{array}{l}\text { B1 vitamini } \\
\text { modifiyeli } \\
\text { 3-aminopropil } \\
\text { silika jel }\end{array}$ & $\mathrm{Pb}$ (II), $\mathrm{Hg}(\mathrm{II})$ & 5 & $9,54-39,4$ & 16 \\
\hline $\begin{array}{l}\text { P(VIM/AAc/ } \\
\text { HEMA) hydrojel }\end{array}$ & $\mathrm{Pb}(\mathrm{II})$ & 4,5 & 30,38 & 17 \\
\hline $\begin{array}{l}\text { Sistein ile } \\
\text { modifiye edilmiş } \\
\text { 3-aminopropil } \\
\text { silika jel }\end{array}$ & $\mathrm{Pb}$ (II), $\operatorname{Hg}(\mathrm{II})$ & 6 & $12,32-100,6$ & $\begin{array}{l}\mathrm{Bu} \\
\text { Çalışma }\end{array}$ \\
\hline
\end{tabular}

\section{TEŞEKKÜR}

Bu çalışma FEN-C-YLP-110915-0447 numaralı proje kapsamında Marmara Üniversitesi Bilimsel Araştırma Projeleri Birimi (BAPKO) tarafından desteklenmiş̧ir.

\section{KAYNAKLAR}

[1] Gültekin, S., Sesal, C., Kayhan, F.E. (2016). İstanbul ili Anadolu yakası doğal kaynak sularının kimyasal analizlerinin değerlendirilmesi. Marmara Fen Bilimleri Dergisi, 28(4), 132-140.

[2] Kahvecioğlu, Ö., Kartal, G., Güven, A., Timur, S. (2003). Metallerin çevresel etkileri-I, TMMOB Metalurji Mühendisleri Odası Metalurji Dergisi, 136, 47-53.

[3] Özbolat, G., Tuli. A. (2016). Ağır metal toksisitesinin insan sağlığına etkileri. Arşiv Kaynak Tarama Dergisi, 25(4), 502521.

[4] Barakat, M. A. (2011). New trends in removing heavy metals from industrial wastewater. Arabian Journal of Chemistry, 4(4), (2011) 361-377.

[5] Choi, J. W., Chung, S.G., Hong, S.W., Kim, D.J., Lee, S.H. (2012). Development of an environmentally friendly adsorbent for the removal of toxic heavy metals from aqueous solution. Water Air Soil Pollut., 223(4), 1837-1846.

[6] Bulut, Y., Tez, Z. (2007). Removal of heavy metals from aqueous solution by sawdust adsorption. Journal of Environmental Sciences, 19(2), 160-166.

[7] Aydın, H., Bulut, Y., Yerlikaya, Ç. (2008). Removal of copper (II) from aqueous solution by adsorption onto low-cost adsorbents. Journal of Environmental Management, 87(1), 37-45.

[8] Sağ, Y., Yalçuk, A., Kutsal, T. (2000). Mono and multi component biosorption of heavy metal ions on Rhizopusarrhizus in a CFST. Process Biochemistry, 35(8), 787-799.

[9] Goswami, A., Singh, A. K. (2002). Silica gel functionalized with resacetophenone: synthesis of a new chelating matrix and its application as metal ion collector for their flame atomic absorption ion collector for their flame atomic absorption spectrometric determination, Analytica Chimica Acta, 454(2), 229-240.

[10] Çubuk, S., Fırlak, M., Kök Yetimoğlu, E., Kahraman, M. V. (2014). Moleküler olarak baskilanmiş çapraz bağlanan hidrojeller ile sulu çözetideki altin iyonlarinin adsorpsiyonu. Marmara Fen Bilimleri Dergisi, 26(3), 115-120.

[11] Radi, S., Tighadouini, S., Bacquet, M., Degoutin, S., Cazier, F., Zaghrioui, M., Mabkhot, Y.N. (2014). Organically modified silica with pyrazole-3-carbaldehyde as a new sorbent for solid-liquid extraction of heavy metals. Molecules, 19(1), 247-262.

[12] Leopold, N., Cîntă-Pînzaru, S., Baia, M., Antonescu, E., Cozar, O., Kiefer, W., Popp, J. (2005). Raman and surface-enhanced Raman study of thiamine at different $\mathrm{pH}$ values. Vibrational Spectroscopy, 39(2), 169-176.

[13] Kara A., Uzun L., Beşirli N., Denizli A. (2004). Poly(ethylene glycol dimethacrylate-n-vinyl imidazole) beads for heavy metal removal. Journal of Hazardous Material,106(2-3), 93-99.

[14] Ercan, Ö., Aydın, A. (2013). Removal of mercury, antimony, cadmium and lead from aqueous solution using 1,3,5-trithiane as an adsorbent. J. Braz. Chem. Soc., 24(5), 865-872.

[15] Abdel-Fattah T., Mahmoud M.E. (2011). Heavy metal ions extraction from aqueous media using nanoporous silica. Chemical Engineering Journal, 175: 117-123, (2011). 
[16] Deniz, S., Tasci, N., Yetimoglu, E. K., Kahraman, M. V. (2017). A new thiamine functionalized silica microparticules as a sorbent for removal of lead, mercury and cadmium ions in aqueous media. J. Serb. Chem. Soc., 82(2), 215-226.
[17] Firlak, M., Yetimoğlu, E. K., Kahraman, M. V., Apohan, N. K., Deniz, S. (2010). Removal of lead and cadmium ions from aqueous solutions using sulphur and oxygen donor ligand bearing hydrogels. Separation Science and Technology, 45(1), 116-128. 